\title{
Fast anaerobic digestion of complex substrates via immobilized biofilms in a novel compartmentalized reactor design
}

Gonzalez Londoño, Jorge E.; Uller, Bjarne; Sørensen, Hanne R.; Meyer, Anne S.

Published in:

Biochemical Engineering Journal

Link to article, DOI:

10.1016/j.bej.2018.12.023

Publication date:

2019

Document Version

Peer reviewed version

Link back to DTU Orbit

Citation (APA):

Gonzalez Londoño, J. E., Uller, B., Sørensen, H. R., \& Meyer, A. S. (2019). Fast anaerobic digestion of complex substrates via immobilized biofilms in a novel compartmentalized reactor design. Biochemical Engineering Journal, 143, 224-229. https://doi.org/10.1016/j.bej.2018.12.023

\section{General rights}

Copyright and moral rights for the publications made accessible in the public portal are retained by the authors and/or other copyright owners and it is a condition of accessing publications that users recognise and abide by the legal requirements associated with these rights.

- Users may download and print one copy of any publication from the public portal for the purpose of private study or research.

- You may not further distribute the material or use it for any profit-making activity or commercial gain

- You may freely distribute the URL identifying the publication in the public portal 


\section{Accepted Manuscript}

Title: Fast anaerobic digestion of complex substrates via immobilized biofilms in a novel compartmentalized reactor design

Authors: Jorge E. Gonzalez Londoño, Bjarne Uller, Hanne R. Sørensen, Anne S. Meyer

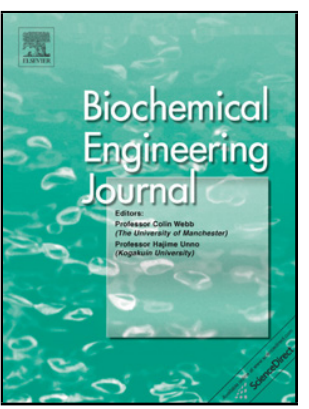

PII: S1369-703X(18)30444-3

DOI: $\quad$ https://doi.org/10.1016/j.bej.2018.12.023

Reference: $\quad$ BEJ 7121

To appear in: Biochemical Engineering Journal

Received date: $\quad 3$ August 2018

Revised date: $\quad 27$ December 2018

Accepted date: $\quad 28$ December 2018

Please cite this article as: Londoño JEG, Uller B, Sørensen HR, Meyer AS, Fast anaerobic digestion of complex substrates via immobilized biofilms in a novel compartmentalized reactor design, Biochemical Engineering Journal (2018), https://doi.org/10.1016/j.bej.2018.12.023

This is a PDF file of an unedited manuscript that has been accepted for publication. As a service to our customers we are providing this early version of the manuscript. The manuscript will undergo copyediting, typesetting, and review of the resulting proof before it is published in its final form. Please note that during the production process errors may be discovered which could affect the content, and all legal disclaimers that apply to the journal pertain. 
Fast anaerobic digestion of complex substrates via immobilized biofilms in a novel compartmentalized reactor design

Jorge E. Gonzalez Londoño ${ }^{\mathrm{a}}$, Bjarne Uller ${ }^{\mathrm{a}}$, Hanne R. Sørensen ${ }^{\mathrm{a}}$, Anne S. Meyer ${ }^{\mathrm{b}, *}$

${ }^{a} \emptyset$ rsted A/S, Kraftværksvej 53, DK-7000, Fredericia, Denmark

${ }^{\mathrm{b}}$ Protein Chemistry and Enzyme Technology, DTU Bioengineering, Department of

Biotechnology and Biomedicine, Technical University of Denmark, DK-2800 Lyngby,

Denmark.

*Corresponding author. Address as above, E-mail: asme@dtu.dk (Anne S. Meyer) 


\title{
Graphical abstract
}

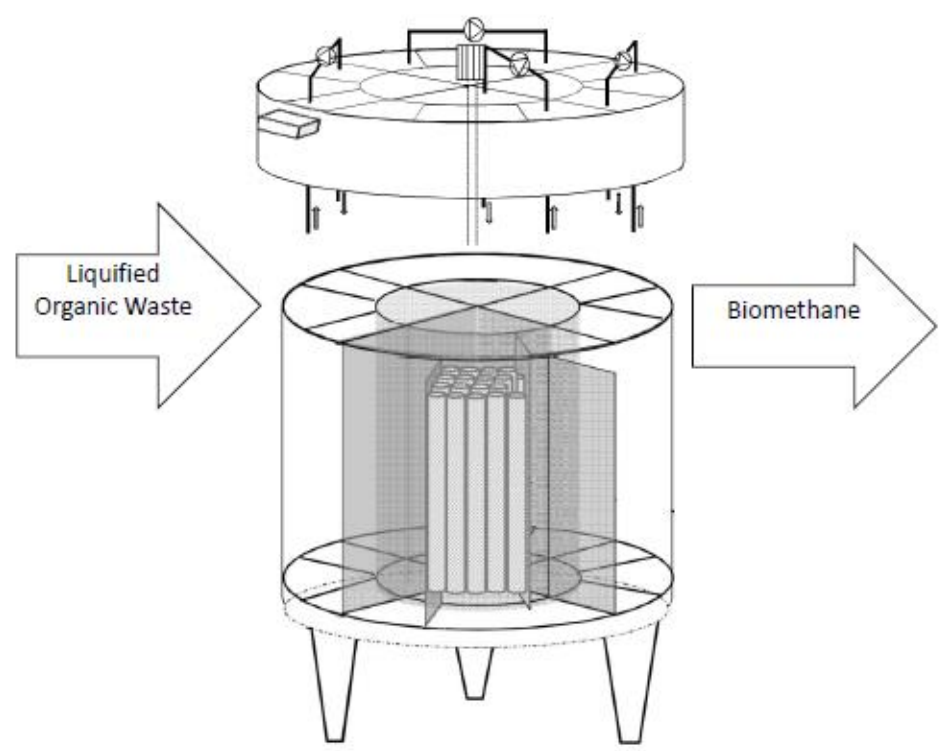

\section{Highlights}

- Compartment reactor design, fixed immobilized biofilms, and controlled flow regime.

- High throughput biogas production on the organic fraction of municipal solids waste.

- Production was minimum $\sim 700 \mathrm{LCH}_{4} \cdot$ day $^{-1}$ with Hydraulic Retention Time of 10 days or less.

- Max. conversion of $20.8 \mathrm{gcod} \cdot$ Lreactor $^{-1} \cdot$ day $^{-1}$ at a Hydraulic Retention Time below 5 days.

- Robust reactor performance at fast feed flow rates during 6 months of running.

\begin{abstract}
Anaerobic digestion of municipal waste is a promising technology for renewable energy production, notably for methane $\left(\mathrm{CH}_{4}\right)$ production. Existing reactor designs have limitations that prevent efficient conversion and high throughput, especially of substrates high in suspended solids. Here, we introduce a novel compartmentalized reactor design encompassing controlled feed flow over fixed microbial biofilms for high rate $\mathrm{CH}_{4}$ production from enzymatically pre-hydrolyzed municipal solid waste. In a 240 liter working volume reactor, the biofilm generation was completed in less than 60 days and $\mathrm{CH}_{4}$ production was minimum $\sim 700 \mathrm{~L} \cdot$ day $^{-1}$ in the ensuing months with a Hydraulic Retention Time (HRT) of 10 days or lower. When the organic load was gradually increased, a reactor productivity of $6 \mathrm{LCH}_{4}$. $\mathrm{L}_{\text {reactor }}{ }^{-1} \cdot$ day $^{-1}$ was achieved. At this point, the reactor processed $20.8 \mathrm{~g}_{\mathrm{COD}} \cdot \mathrm{L}_{\text {reactor }}{ }^{-1} \cdot$ day $^{-1}$ at a HRT below 5 days, maintaining above $70 \%$ of the maximal Chemical Oxygen Demand (COD) conversion rate. Such fast conversion rates and high yields are far beyond what has been reported for other reactor designs, and are a crucial prerequisite for industrial realization of renewable biogas production from municipal solid waste and other organic waste streams.
\end{abstract}


Keywords: Fixed biofilm; reactor design; compartments; suspended particles; municipal solid waste; biogas

\section{Introduction}

In the context of a green and circular economy, anaerobic digestion has recently gained renewed interest as a promising process for renewable energy production from different types of organic waste $[1,2]$. The anaerobic digestion process relies upon microbial consortia to degrade the organics from complex to simple molecules, in turn ultimately producing a methane $\left(\mathrm{CH}_{4}\right)$ rich gas [3]. Under anoxic conditions, the microbial digestion involves both bacteria and archaea. First, bacterial communities degrade and convert the organic material into acetate, hydrogen and carbon dioxide, then specialized archaea convert and consume these products during $\mathrm{CH}_{4}$ production [4]. Such anaerobic conversion processes have lower energy requirements than aerobic treatment [5]. The $\mathrm{CH}_{4}$ produced, or more precisely, the gas product mixture of $\mathrm{CH}_{4}$ and carbon dioxide produced, can be used directly in co-generation of heat and power, or upgraded to almost pure $\mathrm{CH}_{4}$ for introduction into a gas distribution grid [6].

The continuous stirred tank reactor (CSTR) is the most common type of reactor used in anaerobic digestion of heterogeneous biomasses, including e.g. municipal solid waste. In CSTR systems the microorganisms move freely in the reactor liquid, albeit often as flocs, and most of the degradation of the organics therefore occurs in the liquid phase of the reactor [7]. The disadvantages of these types of systems are evident, particularly at low hydraulic retention times (HRTs), where the active biomass is flushed out of the reactor when the HRT becomes lower than the time it takes to regrow the microbial consortium in the reactor. Such digester flush out is often accompanied by acidification of the reactor medium due to buildup of volatile fatty acids and other intermediate products that the methanogenic populations are unable to process sufficiently rapidly [8]. To avoid these limitations, immobilization of the microbes to produce concentrated biofilms that do not flush out has been in focus in the design of anaerobic reactor systems. Immobilization of microbial cells via biofilm formation is based on the natural ability of microorganisms to aggregate and/or attach to solid supports 
[9]. With immobilization of the microbial cells, anaerobic processes can maintain up to one magnitude higher concentration of microorganisms per reactor volume than reactors having the microbes flowing freely in the reactor liquid [10]. With immobilized cells it is moreover possible to decouple the retention time of the microbes from the overall HRT of the conversion process. Very compact and dense biofilms are presumed to lead to mass transfer limitations that prevent fast nutrients exchange in the bioreactor. However, the available data infer that the microbial biofilm populations and the resulting close physical proximity between the immobilized cells rather permit fast nutrient exchange within the biofilm, which favors syntrophic interactions of the communities to accomplish degradation of both complex and simple organic substances [11]. The most common example of a classic anaerobic biofilm reactor is the up-flow anaerobic sludge blanket (UASB) reactor. In the UASB reactor design concept, the capacity of microbes to spontaneously organize into free granular aggregates is exploited, but the granular aggregates are kept separate from the liquid effluents of the anaerobic degradation process thus reducing the flush out and maintaining a dense microbial population in the reactor. However, despite significant advances, including different variations of the original UASB design concept [12], the UASB processes are limited to treat thin and homogeneous substrates containing low levels of suspended solids that do not affect the natural granulation of the sludge.

To overcome the disadvantages of reactors based on granulation, various improvements in reactor design have been reported. The improvements mainly concern biofilm based anaerobic digesters that contain inert supports of different types of materials inside the reactor. These reactor designs are categorized as random or fixed depending on whether the biofilm supports are distributed randomly, or organized in stable positions [13]. In the random immobilization type of design, the biofilm carriers are not distributed in a precise pattern inside the reactor, whereas designs with fixed (or stationary) biofilms have the biofilm support materials placed in a precise configuration pattern that allows the feed stream flow to be directed to maximize its contact with the immobilized microbes. Fixed film reactors can withstand higher concentration of particulate solids with lower risk of clogging than other types of anaerobic digester reactors [14]. 
A common type of substrate with high concentration of particulate solids and high COD is municipal solid waste [15]. This type of substrate mainly consist of waste collected from households, but includes garbage from shops, restaurants, offices, and public institutions [16, 17]. This waste is a mixture of food waste, paper, cotton, various types of trimmings, glass, metals, and plastics, and the organic fraction of this waste, abbreviated OFMSW, has recently been estimated to account for almost half ( $46 \%$ by weight) of the total waste stream [16]. This content of easily biodegradable material combined with the option of simultaneously minimizing waste makes municipal solid waste an attractive candidate for energy production through anaerobic digestion. None of the existing high-rate digesters have until now been utilized to process the entire stream (leachate and residual solids) of liquefied OFMSW [15].

With the objective of maximizing the efficiency of biogas production during municipal solid waste conversion, i.e. maximizing $\mathrm{CH}_{4}$ yield and minimizing the $\mathrm{HRT}$ on as high as possible COD loading, we here assess the performance of a new anaerobic digester design. This novel reactor design comprises internal compartmentalization, controlled flow pattern within the compartments, and microbial biofilm immobilization on fixed carriers having a defined orientation inside the reactor. We examine the performance in pilot scale of this novel fixedfilter anaerobic digester (FAD) reactor design for direct anaerobic treatment of enzymatically pre-hydrolyzed OFMSW with suspended particles.

\section{Materials and methods}

\subsection{Reactor design}

This study was conducted on a pilot scale jacket heated FAD digester of 240 L (media . volume). The reactor is cylindrical in shape and is compartmentalized into four equally dimensioned sections (quarters) by inner walls of stainless steel. Each of the sections have further internal divisions into four subsections separated by baffles (Figure 1a). Substrate filling and effluent withdrawal are accomplished via peristaltic pumps, and mixing is ensured by liquid circulation within each of the separate compartments. This recirculation pump flow was set to $300 \mathrm{~L} \cdot \mathrm{h}^{-1}$ to achieve a flow velocity of approximately $3.12 \cdot 10^{-3} \mathrm{~m} \cdot \mathrm{s}^{-1}$ within each chamber. Differences in the height and depth of the baffles within each subsection have been designed to help control the direction of the flow. Additionally, the design includes an open sedimentation zone at the bottom of each compartment of the reactor, enclosed by the 
positioning of a scraper at the same position as the inner walls dividing the reactor (Figure 1a). In the present study, the fixed filters used for the biofilm immobilization encompassed 8 wide-meshed tubular polyethylene carriers type 150 (Bio-Blok® Expo-Net, Hjørring, Denmark) that were positioned vertically between the baffles. The fixed filters occupied $20 \%$ of the total reactor volume and the specific surface was $150 \mathrm{~m}^{2} \cdot \mathrm{m}^{-3}$. The length of the tubular carriers matched the height of the inner walls of the baffles. The reactor was maintained at $50^{\circ} \mathrm{C}$ throughout the whole experiment via use of a thermostatically controlled water bath.

During operation the feed was introduced into the first compartment of the reactor and left the reactor after the liquid had been routed through all the sections (Figure 1b). The suspended particles that precipitated into the bottom space of the compartments were withdrawn from the process after the scraper operation by means of an eccentric screw pump. The pump was located beneath the reactor posterior to a deeper sedimentation zone in the fourth compartment where the effluent leaves the reactor. To ensure anaerobic conditions the reactor was sealed with fittings and rubber sealing. The levels of biogas that evolved during the anaerobic digestion process were monitored by a gas flow device obtained from Bioprocess Control AB (Lund, Sweden).

\subsection{Composition and analysis of the feed}

The FAD reactor was fed with enzymatically pre-hydrolyzed municipal solid waste, OFSMW, supplied by Renescience A/S (Ørsted A/S, Fredericia, Denmark). The initial seed (inoculum) used in this investigation came from Foulum Biogas, a plant in Denmark treating manure and fiber rich residues from agricultural straw. The feed-in was supplied hourly from an agitated storage tank, which was filled every day to avoid undesired degradation. The substrate was stored at $4{ }^{\circ} \mathrm{C}$ throughout the experimental period. The Total Solids (TS), Volatile Solids (VS) and ash were analyzed according to the standard protocol from the US National Renewable Energy Laboratory [18]. Suspended solids were also determined gravimetrically after filtration through Whatman Grade 934-AH RTU filters. Chemical oxygen demand (COD) and volatile fatty acids (VFAs) in the digestate were quantified using the Hach LCK514 COD and LCK365 Organic Acid cuvette tests using a DR 3900 spectrophotometer (Hach, Düsseldorf, Germany). 
Gas composition was determined via gas chromatography, (model GC82 Mikrolab Aarhus A/S, Denmark). Quantification of VFAs in the substrate was done by HPLC equipped with an RI detector using a Biorad HPX-87H column (Hercules, CA; USA) at $63{ }^{\circ} \mathrm{C}$ with $5 \mathrm{mM}$ $\mathrm{H}_{2} \mathrm{SO}_{4}$ as eluent at a flow rate of $0.6 \mathrm{~mL} \cdot \min ^{-1}[19]$.

\subsection{Strategy and operation of the FAD pilot scale system}

During the development studies of the FAD reactor performed in laboratory scale, the initiation period was estimated to last approximately 60 days. During this period, the biofilm presumably develops from the initial seed, as it perceives a steady increase of the organic load. The strategy involved commencing the feed rate at an HRT of 50 days, increasing the daily in-take while maintaining a threshold of VFAs below $2 \mathrm{~g} \cdot \mathrm{L}^{-1}$ to avoid organic overloading. The biofilm initiation phase was finalized when the system achieved a HRT of 10 days, a point described as critical for microbial flush-out [20]. After completion of the initiation, the feed-in flow was halted and was then re-commenced after 3 days at the most recent flow rate, to verify the biofilm formation and its robustness. Thereafter the organic load was increased steadily until reaching the inflection point of productivity. At the inflection point, an increase of the organic load does not result in an increase of the productivity for the studied process. Following the initiation of the biofilm, the organic load was increased to assess the yields and productivity of this reactor at lower HRTs treating pre-hydrolyzed OFMSW. The experiment lasted 211 days from the seeding day.

\section{Results}

\subsection{Substrate and inoculum characterization}

The $\mathrm{pH}$ of the pre-hydrolyzed OFMSW was approximately 4, ranging from $\mathrm{pH}$ 3.8-4.6 during the experiment, and the OFMSW was characterized by having a high COD of which $\sim 60 \%$ was measured as soluble (Table 1). From the quantification of metabolites in the soluble fraction, $43.2 \pm 12.3 \mathrm{~g} \cdot \mathrm{L}^{-1}$ were analyzed as VFAs (Table 1 ), accounting for approximately $60 \%$ (by weight) of the measured VS. This level of solubilized VFAs was consistent with the low $\mathrm{pH}$ of the feed and most likely due to some metabolism of acidogenic bacteria taking place during the pre-hydrolysis treatment. In the substrate, some larger particles consistent with food residues, although not larger than $3 \mathrm{~mm}$, were also observed. Characterization of the seed material showed that it had $\mathrm{pH}$ of 8.1 with $0.41 \mathrm{~g} \cdot \mathrm{L}^{-1}$ of VFAs (data not shown). 


\subsection{The initiation period}

At the beginning of the experiment, the reactor was inoculated with seed material that was recirculated through all the compartments while achieving the process temperature of $50{ }^{\circ} \mathrm{C}$. Before the first feed-in at the planned feed flow regime, the reactor was fed with substrate pulses of $5 \mathrm{~L} \cdot \mathrm{d}^{-1}$ to test the inoculum health and ensure that the reactor system was tight. The first gas production was registered on day 3 after inoculation. From then on, the flow rate of the reactor was increased gradually from a HRT of 50 days (Figure 2). Previous lab scale experiments had shown that the inoculum was fit and acclimatized to convert a substrate with the characteristics of the pre-hydrolyzed OFMSW, which is consistent with the rapid evolution of gas production. There was no significant fluctuation in the composition of the substrate during the entire experiment (data not shown). The gas production and the COD balance were used as indicators to monitor process stability.

During the initiation period, the process was operated for 56 days until the nominal flow rate of $24 \mathrm{~L}_{\text {substrate }} \cdot$ day $^{-1}$ was achieved. It was possible to induce a rapid decrease of the HRT (Figure 2). The VFA pool was maintained below $2 \mathrm{~g} \cdot \mathrm{L}^{-1}$ by actively trimming the flow rate, which explains the fluctuations in the HRT recorded over time (Figure 2 and Figure 4). During the initiation phase, from a HRT of 50 days at day 1 until achieving an HRT of 20 days at day 26 (Figure 2), the average $\mathrm{CH}_{4}$ yield was calculated to be $0.266 \mathrm{LCH}_{4} \cdot \mathrm{g}_{\mathrm{COD}}{ }^{-1}$ (Figure 3). Surprisingly, the methane yield from day 26 through 56 remained at a similar level and was calculated to be $0.273 \mathrm{~L}_{\mathrm{CH} 4} \cdot \mathrm{gCOD}^{-1}$ (Figure 3). This constant yield level verified that the compartmentalized reactor could perform robustly despite the rapid increase of the substrate flow rate.

\subsection{Reactor performance}

\subsubsection{Yields}

After reaching a HRT of 10 days at day 56 of the experiment, the feed-in was deliberately halted for 3 days in order to verify the biofilm formation. At this time, the VFA concentration dropped to $0.8 \mathrm{~g} \cdot \mathrm{L}^{-1}$ (Figure 4 ). After the feed restoration, the FAD reactor produced the same yield of around $0.27 \mathrm{LCH} \cdot \mathrm{gCOD}^{-1}$ as previously registered after 4 days (day 63). Thereafter, $\mathrm{CH}_{4}$ production was $700-720 \mathrm{LCH}_{4}\left(\sim 3 \mathrm{LCH}_{4} \cdot \mathrm{L}_{\text {reactor }}{ }^{-1} \cdot\right.$ day $\left.^{-1}\right)$ during the $60-80$ 
days ensuing with an average HRT of 10 days (Figure 2). At this time, the VFA concentration peaked by exceeding $3.1 \mathrm{~g} \cdot \mathrm{L}^{-1}$, while the $\mathrm{pH}$ had dropped to 7.4 (Figure 4 ). Within the next days, the VFA pool returned to a level of 1-1.5 $\mathrm{g} \cdot \mathrm{L}^{-1}$ (Figure 4), confirming the rapid ability of the reactor to recover its performance. After achieving a HRT of 10 days, the feed flow rate was increased to assess the yields under that regime. After this period the organic load was gradually increased achieving COD conversion higher than $70 \%$ of predictable at an organic loading rate of $20.8 \mathrm{~g}_{\mathrm{COD}} \cdot \mathrm{L}_{\text {reactor }}{ }^{-1} \cdot$ day $^{-1}$ (Figure 3 ). From the results obtained it was evident that the methane yields $\left(\mathrm{LCH}_{4} \cdot \mathrm{gCOD}^{-1}\right)$ remained almost constant at lower HRTs (Figure 3).

\subsubsection{Productivity}

During both the start-up and the organic load increase phase, the productivity increased steadily with decreasing HRT until a remarkable methane production of almost $6 \mathrm{~L}_{\mathrm{CH} 4}$. $\mathrm{L}_{\text {reactor }}{ }^{-1} \cdot$ day $^{-1}$ was achieved (Figure 5). It was possible to maintain this high production regime for 8 days in a row as evident from the $\mathrm{CH}_{4}$ levels achieved during the last days of the experiment (Figure 2).

However, when the flow rate was increased further after day 200, the reactor was not able to sustain the high productivity and a rapid decrease of the gas production was observed. Hence, at day 203 of the experiment, the gas production leveled off after the flow rate was increased to $80 \mathrm{~L}_{\text {subtrate }} \cdot$ day $^{-1}$, equivalent to an HRT of 3 days (Figure 2). The most likely explanation for this productivity limit is acidification of the reactor media because at this regime, the $\mathrm{pH}$ of the reactor media fell to less than $\mathrm{pH} 7$ (Figure 4) which thus appeared to have a detrimental effect on the methanogenic activity, leading to the process collapse. It was possible to diagnose the process failure and stop the feed pump at a load of 40 liters.

\section{Discussion}

During the treatment of complex substrates utilizing fixed film anaerobic digesters, in particular biomass substrates characterized by high concentrations of suspended particles, clogging of the filters is probably the most common problem encountered. The saturation of filters may then lead to further complications such as channeling inside the reactors, accumulation of solids in certain zones of the reactor, and blockage of the recirculation 
pumps. The FAD reactor features a combination of design elements not described before, that seem to contribute to avoiding this kind of complications. The compartmentalization of the reactor with the introduction of inner baffles permits a controlled flow of the digesting liquid parallel to the surface of the filters where the biofilm develops (Figure 1b). The digestate leaving the reactor is liquid, and before it leaves the reactor it has passed through all the sections in a directed flow pattern. For this reason, there is an improved retention of unprocessed material before the liquid digestate leaves the process.

The pilot reactor design studied here had four pumps actively recirculating the media through each section. The suction and discharge points of the recirculation pumps were positioned in the upper part of the reactor and the connection points (Figure 1a). The overhead positioning of these elements may also be favorable with respect to preventing clogging since the heaviest particles evade the flow stream as they remain at the bottom of the reactor. Even though most studies for fixed film reactors deal with thin substrates, the operation of a unidirectional flow can lead to problems with clogging [21]. The active discharge of liquid from the top from each recirculation stream provides for an additional source of mixing in the absence of mechanical agitation. In high-rate anaerobic digestion processes, it is also assumed that the gas bubble dispersion can contribute to the process by promoting local back-mixing. When considering scale-up of the reactor, the dimensioning of the pump capacity can be maintained constant by constructing additional compartments, maintaining similar flow regimes.

In the reactor type investigated here, the compartmentalization design and the flow regime had been carefully designed to foster an improved transport of substances and to maximize the contact between the liquid feed stream and the immobilized cells in the fixed biofilm causing both improved colonization [22] and favorable conversion. The data obtained with the high flow rates of more than $3 \cdot 10^{-3} \mathrm{~m} \cdot \mathrm{s}^{-1}$ within each chamber suggest that the intended desirable mass transfer was achieved. Modeling of the nutrient and metabolites flow in the liquid and notably inside the biofilms are required, however, to fully verify the conversion dynamics and to substantiate the theorem that an optimal mass transport of nutrient flow is a determinant factor affecting the performance of the reactor. In this reactor design, it is also possible to recirculate the liquid streams within the four compartments. In standard operation, 
the liquid recirculates through the baffles of each section and overflows to the next dictated by the flow rate of the feed (Figure 1b).

The type of carrier medium may significantly affect the attachment and detachment properties of the microbial biofilm [23]. The polyethylene carriers employed in the FAD were selected as support for biofilm growth as this material enhances rapid adhesion of microbial cells. This carrier is moreover characterized by a threaded pattern and a rough surface, described to be important since void materials have been shown to be less prone to clogging since it is easier to remove the excess of solids accumulated by simple process shear forces [24]. Furthermore, the threaded structure of the carrier allowed horizontal dispersion of the liquid between the filters, therefore increasing the access of nutrients to the biofilm that inevitably forms behind the tubular carriers. At the termination of the experimental phase, the FAD reactor was drained to assess whether there were particles clogging the filters. By visual inspection it was confirmed that all the filters had been exposed to the digesting media without obstruction, since it was possible to see the bottom of the reactor.

The findings that the methane yields $\left(\mathrm{LCH}_{4} \cdot \mathrm{gCOD}^{-1}\right)$ remained almost constant at low HRTs (Figure 3) were unexpected. A slight drop-in yield was predictable since at those regimes, there may be a flush-out of organic compounds that have not been digested. The ability of the compartmentalized FAD reactor to maintain high COD converting efficiencies (Figure 5) despite the rapid flow rates, i.e. low HRTs, is remarkable, and the yields attained signifies a distinct performance of the reactor compared to what has been reported by others for single stage digestion of OFMSW [20, 25]. Different studies performed on similar substrates indicate that the maximum organic loading rates for anaerobic digestion of this type is in the range of $10.5-17 \mathrm{~g}_{\mathrm{COD}} \cdot \mathrm{L}_{\text {reactor }}{ }^{-1} \cdot \mathrm{day}^{-1}$ and the data suggest that higher organic loadings may lead to irreversible acidification $[25,26]$. In this experiment it has been possible to operate at even higher concentrations of organics without compromising COD loss greater than $30 \%$. In figure 5, it can be seen that the COD removal at the highest retention times is larger than $90 \%$. The concentration of COD in the effluent is in correspondence with the data obtained from the gas production and the yields perceived during the experimental phase. At the highest rates, there can be observed a decrease in the methane yields that parallels the increasing concertation of COD in the media, especially when the in-flow rate is the highest. 
To our knowledge, this is the first study in which it has been possible to digest the whole slurry of OFMSW in a high rate reactor without any type of previous separation.

Another important aspect of the reactor design employed in the present study is the scraper. By actuation every 5th day it effectively removed large quantities of the deposited solids. This removal prevented clogging and channeling in the reactor compartments, permitting the digestion media to be recycled efficiently and maintaining the high area of contact between the microbial biofilms and the liquid. The solids that were evacuated via the scraper through the eccentric snake pump were predominantly suspended solids having more than $30 \%$ ash content. The operation of the scraper at the bottom of the FAD reactor may be optimized to remove or retain certain sedimentable particles from the anaerobic process depending on the nature of the biomass and on the hydrolysis rate of the particulate dry matter at the chosen retention time. If the substrate contains high levels of inert material, such as the substrate used in the present study, it will be convenient to evacuate the sedimented sludge to reduce plugging of the reactor compartments and avoid the decrease of active volume. In the present work, the scraper was operated every 5 days removing $1 \%$ by volume of the reactor's volume content estimated to be close to the inert content at an HRT of 10 days.

\section{Conclusion}

The yields of 0.2-0.3 $\mathrm{L} \mathrm{LCH}_{4} \cdot \mathrm{gCOD}^{-1}$ and productivities of 2-6 $\mathrm{L}_{\mathrm{CH} 4} \cdot \mathrm{L}_{\text {reactor }}{ }^{-1} \cdot$ day $^{-1}$ achieved at HRTs below 10 days with the pilot scale FAD reactor fed high COD OFMSW was better than all other anaerobic digestion data reported. The biofilm developed during the first two months of reactor operation. The biofilm could recommence production after 3 days of ceased inflow at an HRT of 10 days, confirming robust attachment of active microorganisms. The compartmentalization and flow regime allowing efficient feed-immobilized biofilm contact plus other distinct reactor design features allowed for high efficiency and lengthy operation without clogging problems.

\section{Funding}

This work was supported by Ørsted A/S, Denmark and The Technical University of Denmark.

\section{Conflict of interest statement}


All authors declare no conflict of interest. J.E. Gonzalez Londoño and B. Uller are inventors of a patent related to methods and reactor design for anaerobic digestion. Authors J.E. Gonzalez Londoño, B. Uller, and H.R. Sørensen are employed at Ørsted (formerly DONG Energy), a Danish company which develops, constructs, and operates bioenergy plants. 


\section{References}

[1] S. Dahiya, A.N. Kumar, J.S Sravan, S. Chatterjee, O. Sarkar, S.V. Mohan, Food waste biorefinery: Sustainable strategy for circular bioeconomy, Bioresour. Technol. 248 (2018) 2-12.

[2] S. Maina, V. Kachrimanidou, A. Koutinas, A roadmap towards a circular and sustainable bioeconomy through waste valorization, Curr. Opin. Gr. Sust. Chem. 8 (2017) 18-23.

[3] C. Sawatdeenarunat, K.C. Surendra, D. Takara, H. Oechsner, S. Kumar, Anaerobic digestion of lignocellulosic biomass: Challenges and opportunities, Bioresour. Technol. 178 (2015) 178-186.

[4] C. Welte, U. Deppenmeier, Bioenergetics and anaerobic respiratory chains of aceticlastic methanogens - Bioenergetics, Biochim. Biophys. Acta 1837 (2014) 1130-1147.

[5] G. Lettinga, A.C. Haandel, Anaerobic digestion for energy production and environmental protection, in: Johansson, T.B. et al. (Eds.), Renewable energy: Sources for fuels and electricity, Island press, Covelo, California, (1993) pp. 817-839.

[6] Q. Zhang, J. Hu, D. Lee, Biogas from anaerobic digestion processes: Research updates. Renew. Energ. 98 (2016) 108-119.

[7] E.A. Echiegu, Kinetic models for anaerobic fermentation processes-A review, Am. J. Biochem. Biotechnol. 11 (2015) 132-148.

[8] S. Lerm, A. Kleyböcker, R. Miethling-graff, M. Alawi, M. Kasina, M. Liebrich, H. Würdemann, Archaeal community composition affects the function of anaerobic codigesters in response to organic overload, Waste Manag. 32 (2012) 389-399. 
[9] R. Cresson, P. Dabert, N. Bernet, Microbiology and performance of a methanogenic biofilm reactor during the start-up period, J. Appl. Microbiol. 106 (2009) 863-876.

[10] S. Langer, D. Schropp, F.R. Bengelsdorf, M. Othman, M. Kazda, Dynamics of biofilm formation during anaerobic digestion of organic waste, Anaerobe 29 (2014) 44-51.

[11] G. O'Toole, H.B. Kaplan, R. Kolter, Biofilm formation as microbial development, Ann. Rev. Microbiol. 54 (2000) 49-79.

[12] R. Escudié, R. Cresson, J.-P. Delgenès, N. Bernet, Control of start-up and operation of anaerobic biofilm reactors: An overview of 15 years of research, Water Res. 45 (2011) $1-10$.

[13] F. Habouzit, G. Gévaudan, J. Hamelin, J.P. Steyer, N. Bernet, Influence of support material properties on the potential selection of Archaea during initial adhesion of a methanogenic consortium, Bioresour. Technol. 102 (2011) 4054-4060.

[14] A. Wilkinson, K.J. Kennedy, Anaerobic digestion of corn ethanol thin stillage in batch and by high-rate down flow fixed film reactors, Water Sci. Technol. 66 (2012) 18341841.

[15] M. Ye, J. Liu, C. Ma, Y-Y. Li, L. Zou, G. Qian, Z.P. Xu, Improving the stability and efficiency of anaerobic digestion of food waste using additives: A critical review. J. Clean. Prod. 192 (2018) 316-326.

[16] R. Campuzano, S. González-Martínez, Characteristics of the organic fraction of municipal solid waste and methane production: A review, Waste Manag. 54 (2016) 3-12.

[17] European Commission. Eurostat. 2017. http://ec.europa.eu/eurostat/statisticsexplained/index.php/Glossary:Municipal_waste (Accessed July 30. 2018).

[18] A. Sluiter, B. Hames, D. Hyman, C. Payne, R. Ruiz, C. Scarlata, J. Sluiter, D. Templeton, J. Wolfe, Determination of total solids in biomass and total dissolved solids 
in liquid process samples, NREL Technical Report NREL/TP-510-42621, 2008 www.nrel.gov/biomass/analytical_procedures.html (Accessed January 2018).

[19] M. Ambye-Jensen, S.T. Thomsen, Z. Kádár, A.S. Meyer, Ensiling of wheat straw decreases the required temperature in hydrothermal pretreatment, Biotechnol. Biofuels 6 (2013) 116-125.

[20] H. Hartmann, B.K. Ahring, Strategies for the anaerobic digestion of the organic fraction of municipal solid waste: An overview, Water Sci. Technol. 53 (2006) 7-22.

[21] J. Mumme, B. Linke, R. Tölle, Novel upflow anaerobic solid-state (UASS) reactor, Bioresour. Technol. 101 (2010) 592-599.

[22] M. Harvey, C.W. Forsberg, T.J. Beveridge, Methanogenic activity and structural characteristics of the microbial biofilm on a needle-punched polyester support, Appl. Environ. Microbiol. 48 (1984) 633-638.

[23] C. Sheli, R. Moletta, Anaerobic treatment of vinasses by a sequentially mixed moving bed biofilm reactor, Water Sci. Technol. 56 (2007) 1-7.

[24] J.V. Thanikal, M. Torrijos, F. Habouzit, R. Moletta, Treatment of distillery vinasse in a high rate anaerobic reactor using low density polyethylene supports, Water Sci. Technol. 56 (2007) 17-24.

[25] N. Nagao, N. Tajima, M. Kawai, C. Niwa, N. Kurosawa, Maximum organic loading rate for the single-stage wet anaerobic digestion of food waste, Bioresour. Technol. 118 (2012) 210-218.

[26] F. Oliveira, K. Doelle, Anaerobic digestion of food waste to produce biogas: A comparison of bioreactors to increase methane content - A Review, J. Food Process. Technol. 6 (2015) 8-10. 
Table 1. Composition of the enzymatically pre-hydrolyzed organic fraction of municipal solid waste (OFMSW) used in this study.

\begin{tabular}{lr}
\hline Component & Measured value \\
\hline COD & $101 \pm 2.6 \mathrm{~g} / \mathrm{L}$ \\
Soluble COD & $63 \pm 2.7 \mathrm{~g} / \mathrm{L}$ \\
Total solids & $8.6 \pm 0.70 \%$ weight/vol \\
Volatile Solids (VS) & $6.9 \pm 0.70 \%$ weight/vol \\
Suspended solids & $3.0 \pm 0.04 \%$ weight/vol \\
Ash & $1.7 \pm 0.09 \%$ weight/vol \\
\hline
\end{tabular}




\section{Figure legends}

Figure 1. a) Schematic diagram of the pilot scale FAD reactor. b) Schematic diagram of the flow pattern in the FAD reactor c) Placement of carriers inside the FAD reactor: Top image within a single compartment; bottom image throughout the four compartments in the reactor. Grey arrows indicate underflow; White arrows indicate overflow; Black arrows correspond to pump recirculation.

Figure 2. Evolution of daily methane production (circle symbols, liters (L)) and Hydraulic Retention Time (triangle symbols, HRT, days) with time (days).

Figure 3. Methane yields $\left(\mathrm{L}_{\mathrm{CH}_{4}} \cdot \mathrm{gCOD}^{-1}\right)$ and Volumetric Productivity $\left(\mathrm{L}_{\mathrm{CH}_{4}} \cdot \mathrm{L}_{\text {reactor }}{ }^{-1} \cdot\right.$ day $\left.^{-1}\right)$ during the experimental phase versus HRT (days).

Figure 4. Evolution of $\mathrm{pH}$ and VFA concentration levels $\left(\mathrm{g} \cdot \mathrm{L}^{-1}\right)$ during the experiment.

Figure 5. Progress of COD removal $(\%)$ and COD levels in the effluent $\left(\mathrm{g}_{\mathrm{COD}} \cdot \mathrm{L}_{\mathrm{COD}}{ }^{-1}\right)$ during the course of the anaerobic digestion (days). 

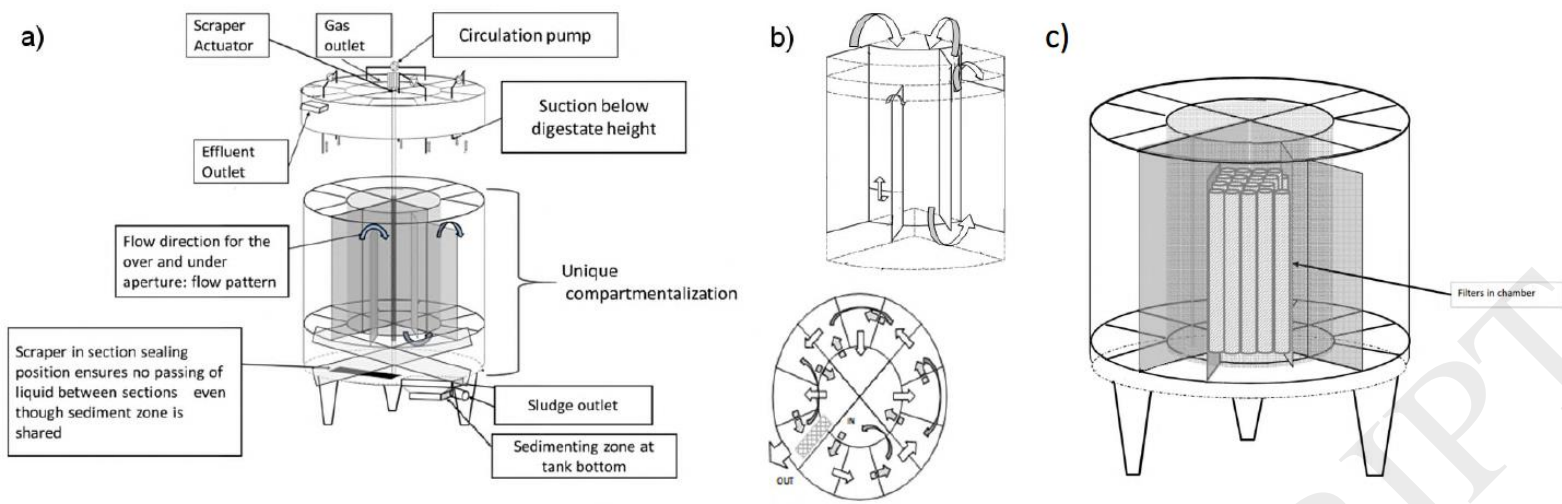

Fig 1. 


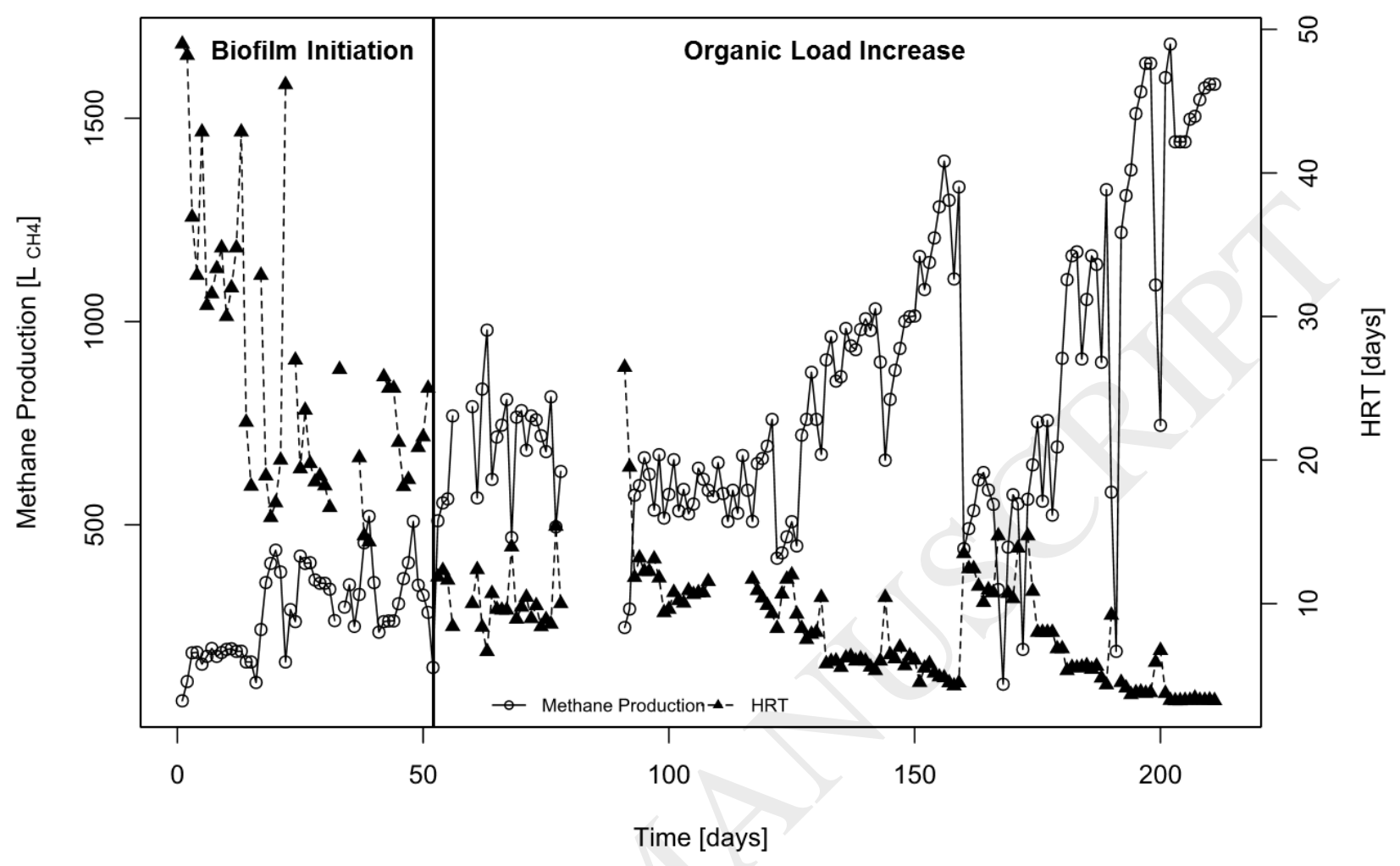

Fig 2. 


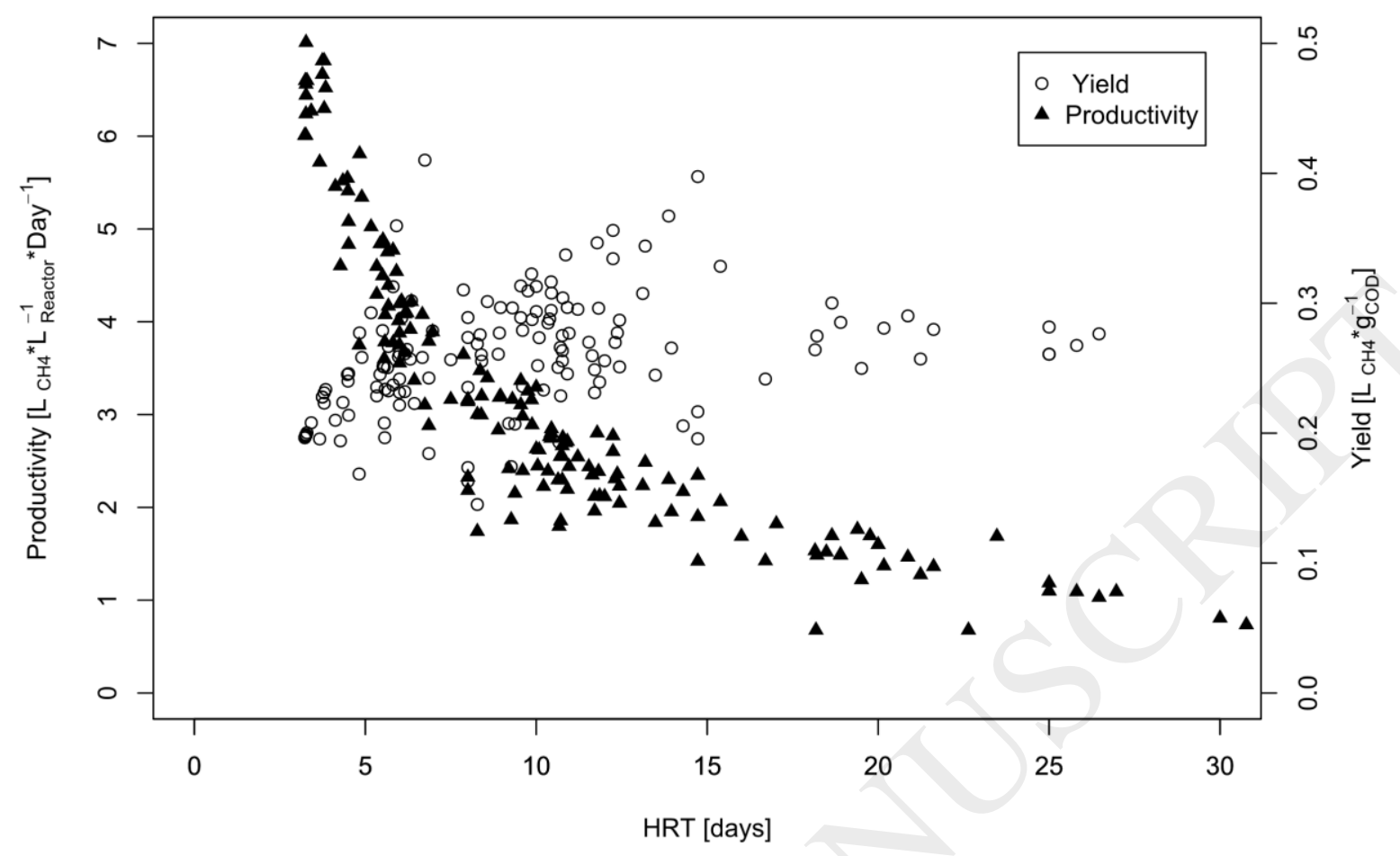

Fig 3. 


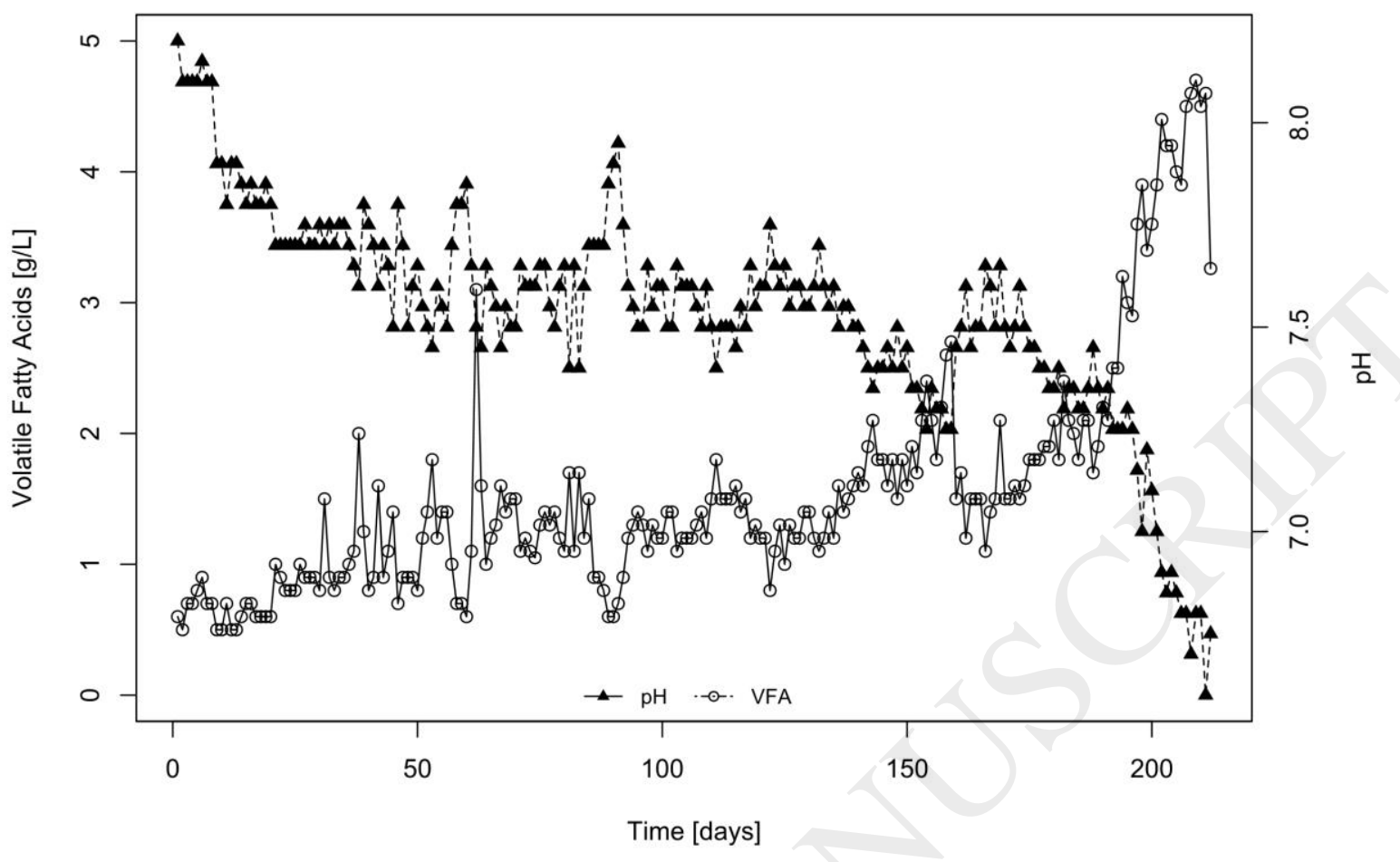

Fig 4. 


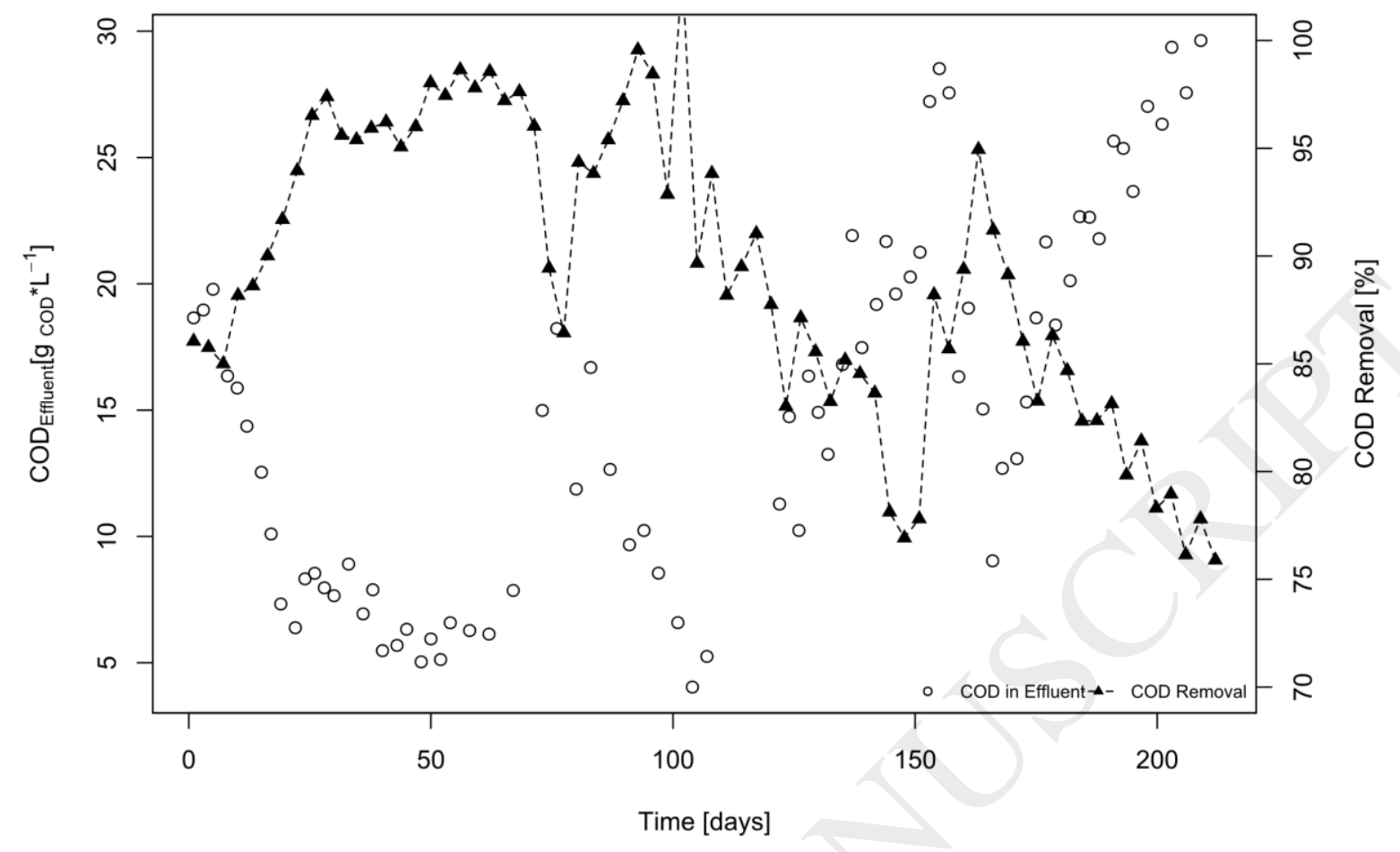

Fig 5. 